\title{
Experimental Optimization of Selective Hydrazine Detection in Flow Injection Analysis Using a Carbon Paste Electrode Modified with Copper Porphyrin Occluded into Zeolite Cavity
}

\author{
Silvia V. Guerra*, Lauro T. Kubota*†, Claudia R. XAVIER** and Shirley NaKagaki** \\ *Instituto de Química-Unicamp, P. O. Box 6154, 13083-970 Campinas, SP, Brazil \\ **Departamento de Química da Universidade Federal do Paraná, Curitiba, Pr, Brazil
}

\begin{abstract}
A carbon paste electrode modified with copper porphyrin occluded into zeolite cavity was developed for sensing hydrazine in flow system. The sensor presented a high sensitivity and selectivity for hydrazine concentration in the flow system. The flow system was optimized by factorial design considering a two level, three factor factorial design (the factors were applied potential, sampling volume and flow rate). The sensitivity and analytical frequency were considered as the most important parameters for the system. The best condition for the system was sampling volume of $50 \mu 1$, applied potential of $270 \mathrm{mV} v s$. SCE and a flow rate of $1 \mathrm{ml} \mathrm{min}^{-1}$. In this optimized condition, the electrode can improve its sta-

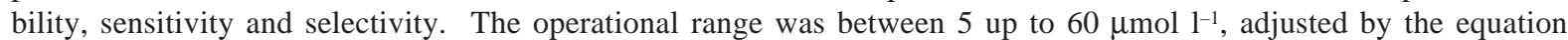
$Y=1.9( \pm 0.1)+0.20( \pm 0.01)\left[\right.$ hydrazine] $-0.0014( \pm 0.0001)\left[\right.$ hydrazine] ${ }^{2}$, with a correlation coefficient of 0.9995 for $n=8$. The analytical frequency was about 70 determinations per hour and the system was stable for at least two months in continuous use.
\end{abstract}

Keywords Experimental optimization, modified zeolite, amperometric sensor, FIA, hydrazine determination

Hydrazine is an organic compound which is very important in industrial, pharmaceutical, fuel cell and biological fields due to its characteristic reactivity. ${ }^{1}$ Hence, hydrazine quantification has a great analytical interest and many attempts have been made to develop sensitive analytical methods for its determination. ${ }^{2}$

Many methods for hydrazine determination based on its redox property are described in the literature. ${ }^{3}$ These methods include alkaline oxidation with permanganate $^{4}$, potentiometric titration ${ }^{5}$ or spectrophotometric determination with addition of 4-dimethyl-aminobenzaldehyde in the hydrazine solution. ${ }^{6}$ Several modifications of these methods were published $;^{7}$ however, they present a relatively long time per analysis, because many steps are necessary, thus increasing the uncertainty of the method.

Methods with amperometric and voltammetric detection are powerful techniques for monitoring oxidizable species. ${ }^{8,9}$ Unfortunately, hydrazine needs a high overpotential for oxidation and conventional electrodes such as glassy carbon are not applicable for these methods. Thus, modified electrodes can be a good alternative for this purpose due to the overpotential minimization. ${ }^{10-14}$

Baldwin and co-workers ${ }^{15,16}$ developed amperometric detectors for hydrazine using electrochemically treated glassy carbon electrodes and carbon paste electrodes modified with cobalt phthalocyanine and employed for

$\doteqdot$ To whom correspondence should be addressed. flow injection analysis. Wang et al. ${ }^{17}$ used cellulose acetate modified with cobalt phthalocyanine mixed with carbon paste to detect hydrazine. Prussian Blue deposited onto glassy carbon electrode was also employed for sensing hydrazine in flow injection analysis by Hou and collaborators ${ }^{18}$, although the potentials applied in these cases were low. The interference of some compounds like cysteine and quinones should be eliminated before the analysis. The porphyrin encapsulation into zeolite cavity may give the selectivity due to the controlled size of the pores, allowing only small species to interact with the catalyst. ${ }^{19}$

The flow injection analysis is a good alternative in analytical chemistry for automation. The cost per analysis will become cheaper due to its rapidity, precision and the possibility to develop different systems for the same purpose. ${ }^{20-22}$ The flow systems generally have several parameters which one must adjust and optimize. However with unidimensional studies it is very hard to get the real best conditions. Based on this context, the mathematical tools such as factorial design can become helpful to optimize the system. ${ }^{23}$ Several works have been published using factorial design in the FIA system optimization $^{24-26}$, however few papers describe the optimization when modified electrodes are used.

An early work ${ }^{19}$ described the development of a sensor for hydrazine using copper porphyrin synthesized into zeolite cavity and a modified carbon paste electrode. The great sensitivity, selectivity and short response time observed for the electrode made it very 


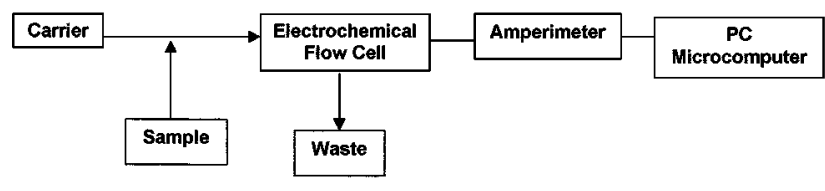

Fig. 1 Scheme of the FIA system for hydrazine determination.

attractive to use in flow systems. Thus, the detection of hydrazine in flow system using the carbon paste electrode modified with copper porphyrin/zeolite as well as the optimization by factorial design are described here.

\section{Experimental}

Synthesis of copper tetraphenylporphyrin into zeolite cavity

The copper porphyrin complex was synthesized into the zeolite cavity according to the procedure described earlier. ${ }^{27}$ A quantity of $5.0 \mathrm{~g}$ of zeolite (type NaY kindly supplied by Petrobrás, Brazil), with an average pore aperture of $8 \mathrm{~nm}$ and the supercage of $13 \mathrm{~nm}$ diameter, was added into $250 \mathrm{ml}$ of a $1.0 \times 10^{-2} \mathrm{~mol} \mathrm{l}^{-1}$ copper sulfate solution and the mixture was shaken for $60 \mathrm{~min}$. After that, the resulting material was filtered, washed with double distilled water and dried in an oven for 12 $\mathrm{h}$ at $80^{\circ} \mathrm{C}$. The amount of copper immobilized by ion exchange on the zeolite surface was determined by atomic absorption spectrometry. To a quantity of $2.0 \mathrm{~g}$ of this copper/zeolite were added $25 \mathrm{ml}$ of propyonic acid, $0.450 \mathrm{ml}$ of pyrrole freshly distilled and $0.660 \mathrm{ml}$ of benzaldehyde for porphyrin synthesis. This mixture was kept at reflux for $18 \mathrm{~h}$ under constant shaking at $140^{\circ} \mathrm{C}$. Then, the mixture was filtered and washed with dichloromethane in a Soxhlet extractor for $50 \mathrm{~h}$. The quantity of copper which remained was determined by atomic absorption spectrometry. The amount of porphyrin was estimated by determining the nitrogen by elemental analysis.

\section{Construction of carbon paste electrode}

A polyethylene syringe was used to construct an electrode to adapt in a flow cell. The carbon paste was put into an extremity of the syringe and pressed to smooth the surface. The electrical contact was made with a copper wire. This syringe was fit into the flow cell. The carbon paste was prepared by mixing graphite (Fluka), modified zeolite and mineral oil in a 3:1:2 ratio. This composition was the best ratio, as described by Guerra and co-workers. ${ }^{26}$

\section{Flow cell}

A homemade flow cell was used to adapt in the flow system to make the electrochemical measurements. The description of the electrochemical flow cell was published already. ${ }^{28}$

\section{Flow system}

The flow system was settled according to the scheme
Table 1 Factors and level values for $2^{3}$ factorial design

\begin{tabular}{llcc}
\hline \multicolumn{1}{c}{ Factor } & Level $(-)$ & Level $(+)$ \\
\hline 1 Sample volume $(\mu \mathrm{l})$ & 50 & 75 \\
2 Carrier flow rate $(\mathrm{ml} / \mathrm{min})$ & 1 & 2 \\
3 Applied potential $(\mathrm{mV})$ & 270 & 320 \\
\hline
\end{tabular}

presented in Fig. 1. The peristaltic pump from Ismatec Model ICP-8 was used in the system to flow control. An amperometric biosensor detector from Universal Sensor Incorporation was used to apply potential and current monitoring. For sample injection was employed an automatic commutation valve B552 from Micronal (Brazil). The signals were collected in a microcomputer.

\section{Optimization by factorial design}

Some parameters such as supporting electrolyte, solution $\mathrm{pH}$ and applied potential range were set by considering the previous experience. ${ }^{26}$ After the previous studies, the three most important factors were defined as sample volume, flow rate and applied potential. Thus, these factors was selected as the principal factors in the factorial design. The three factor-two level factorial design was used to optimize the system using a Factorial software. ${ }^{29}$ The level and factors are listed in Table 1 . The system was optimized considering the sensitivity and analytical frequency.

\section{Results and Discussion}

The flow system was mounted using an electrochemical flow cell described before ${ }^{28}$, making some modifications to adapt the carbon paste electrode in the cell. The carbon paste electrode modified with copper porphyrin zeolite was inserted into the cavity to use as a working electrode. The reference electrode and counter electrode kept the same design as described in the original cell. ${ }^{28}$ Using the information obtained in the studies for the copper porphyrin zeolite modified carbon paste electrode in batch conditions ${ }^{26}$, the composition of the carbon paste, the supporting electrolyte and buffer which obtained the best response in batch conditions ${ }^{26}$ were kept for the flow system. Thus, sodium perchlorate with $\mathrm{pH}$ around 7 was used as carrier in the flow system. The optimization of the system was carried out considering the sensitivity, analytical frequency and interference susceptibility. The potential necessary for hydrazine oxidation using the modified carbon paste electrode was investigated in an early paper; ${ }^{19}$ thus, the potential range to use in this case was near the maximum current obtained in cyclic voltammetry experiments, i.e., between 250 and $350 \mathrm{mV} v$ s. SCE. The effect of solution $\mathrm{pH}$ was checked between 6 and 7.5; the response was almost the same in this range. Thus, the solution $\mathrm{pH}$ was fixed in 7.0 and applied potential was set to investigate its influence in the range of 270 up to $320 \mathrm{mV}$. 


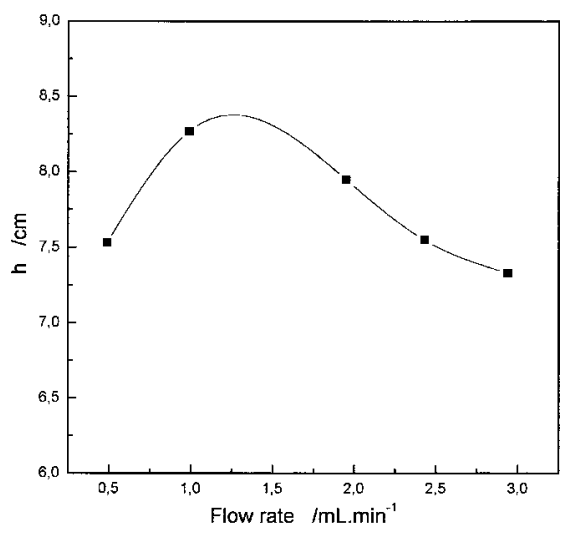

Fig. 2 Electrode response dependence on the flow rate obtained for the system with an applied potential of $320 \mathrm{mV}$. Hydrazine concentration was $50 \mu \mathrm{M}$ and sample volume of $60 \mu 1$.

The effect of flow rate on the response was verified using different flow rates for the same sample volume and concentration. Figure 2 shows the dependence on the electrode response at a function of flow rate. It can be clearly observed that in a flow rate of $1 \mathrm{ml} \mathrm{min}^{-1}$ the higher response is obtained.

The sample volume affects the response of the electrode in a significant way according to the curve shown in Fig. 3. It is clearly shown that the signal increases with the sample volume; however, the analytical frequency decreases due to the washing time. Thus, the sample volume is very important to optimize the system to increase the sensitivity but without a significant decreasing in the analytical frequency. Hence, the sample volumes chosen for factorial design studies were 50 and $75 \mu \mathrm{l}$, values before the maximum response.

These conditions were used to make experiments for three-factor two-level factorial designs for the system optimization, considering the rapidity and sensitivity. The surface of response was considered the peak height. For the best visualization of the response surface, the average of responses was obtained for three replicates for the experiments carried out in a random way; the Taguchi diagram is drawn in Fig. 4. From the diagram it can be verified that for large sample volume the applied potential and flow rate has no effect on the sensitivity. For the low volume the applied potential and flow rate has an important effect, indicating that for lower applied potential gives higher response for low flow rate, but when the flow rate is increased the best response is observed for higher applied potential. This behavior is very interesting, because normally one expects for higher potential better sensitivity, independent of the flow rate. Thus, in this case the interaction effect between applied potential and flow rate is clearly observed. An increase in the response of about $15 \%$ or decreasing $50 \mathrm{mV}$ in the applied potential is surprising for a flow rate of $1 \mathrm{ml} \mathrm{min}{ }^{-1}$. For an applied potential of $270 \mathrm{mV}$, when the flow rate is increased to $2 \mathrm{ml}$ $\min ^{-1}$, the response decreased about $15 \%$; however, if

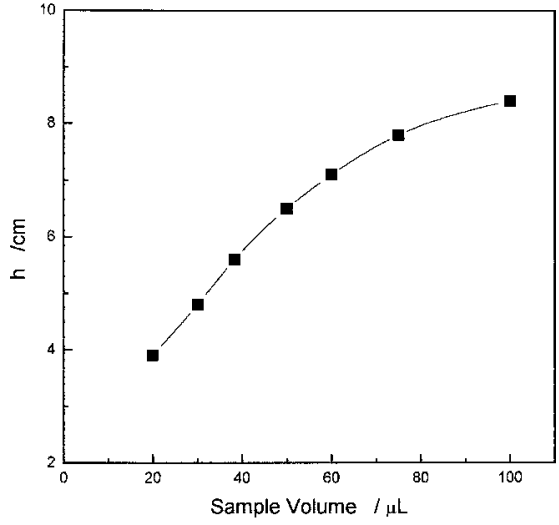

Fig. 3 Effect of sample volume on the FIA system response obtained with a flow rate of $1.0 \mathrm{ml} \mathrm{min} \mathrm{m}^{-1}$, applied potential of $320 \mathrm{mV}$ and hydrazine concentration of $50 \mu \mathrm{M}$.

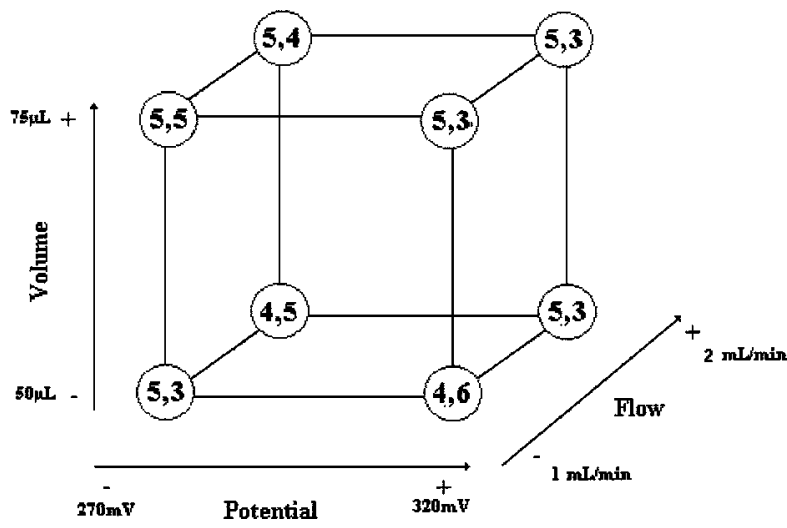

Fig. 4 Taguchi diagram obtained for the responses of the factorial design experiments.

the applied potential was $320 \mathrm{mV}$, the system give the same response. Moreover, $50 \mathrm{mV}$ in the applied potential can represent several interference problems. ${ }^{28}$ Another important aspect is the fair stability when the flow rate is higher than $1.5 \mathrm{ml} \mathrm{min}^{-1}$, in contrast to the flow rate of $1.0 \mathrm{ml} \mathrm{min}{ }^{-1}$. The sample volume has an important effect but $50 \mu \mathrm{l}$ is enough, when low flow rate and applied potential are used; increasing this volume does not affect other factors in a significant way. The estimated effects were calculated using the Factorial software; ${ }^{29,30}$ the results are listed on Table 2. From the estimated effect value for the system the sample volume was verified to be the principal factor that affects the system in a significant way. Only one interaction of two factors is significant, as observed by the values listed on Table 2: the interaction between applied potential and flow rate. The interaction of three factors is very important to be observed in this case, because it clearly shows that in unidimensional studies the optimization of this system would be impossible. The optimized system in this case was flow rate of 1.0

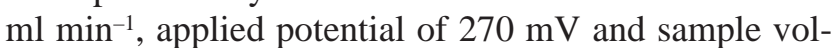
ume of $50 \mu \mathrm{l}$, considering the stability, sensitivity and analytical frequency. 
Table 2 Estimative of principal and interaction effect values for $2^{3}$ factorial design and their standard errors for height $(h)$ in $\mathrm{cm}$

\begin{tabular}{|c|c|c|}
\hline \multicolumn{2}{|l|}{ Average } & $5.15 \pm 0.06$ \\
\hline \multicolumn{3}{|l|}{ Principal effects } \\
\hline \multicolumn{2}{|l|}{1 Sample volume $(\mu \mathrm{l})$} & $0.5 \pm 0.1$ \\
\hline \multicolumn{2}{|c|}{2 Carrier flow rate $(\mathrm{ml} / \mathrm{min})$} & $-0.1 \pm 0.1$ \\
\hline \multicolumn{2}{|l|}{3 Applied potential (mV) } & $0.0 \pm 0.1$ \\
\hline \multirow[t]{3}{*}{ Interaction of two factors } & 12 & $0.0 \pm 0.1$ \\
\hline & 13 & $-0.1 \pm 0.1$ \\
\hline & 23 & $0.2 \pm 0.1$ \\
\hline Interaction of three factors & 123 & $-0.3 \pm 0.1$ \\
\hline
\end{tabular}

The stability and repeatability were checked in the optimized conditions. In Fig. 5 a very good repeatability of the system can be seen, showing a relative deviation of $2 \%$ for 13 injections. The system was stable for at least three months in continuous use and the response kept $76 \%$ of the initial response. The comparison between electrode-to-electrode response showed a good reproducibility and the differences among them was 7\%. A good operational range between 5 - $60 \mu \mathrm{mol} \mathrm{l}^{-1}$ was adjusted for the system. The equation adjusted for the curve was $h=(1.9 \pm 0.1)+(0.20 \pm 0.01)[\mathrm{Hyd}]-(0.0014 \pm 0.0001] \times$ [Hyd] ${ }^{2}$, where $h$ is the peak height in $\mathrm{cm}$ and [Hyd] is the hydrazine concentration in $\mu \mathrm{mol} \mathrm{l}^{-1}$, with a correlation coefficient of 0.9995 for $n=8$. The analytical frequency was 70 samples per hour, showing good rapidity in the analysis. The recovery test carried out with the system presented good results, getting $97 \pm 2 \%$ for solution in concentration of $5 \mu \mathrm{mol} \mathrm{1^{-1 }}$. The detection limit considering the signal to noise ratio as $3: 1$ was $1.0 \mu \mathrm{mol} 1^{-1}$ and the operational limit was $5.0 \mu \mathrm{mol} \mathrm{l}^{-1}$.

The factorial design allowed us to optimize the experimental conditions and thus improve the sensitivity and stability of the system, indicating that it is very important tool for the flow system optimization, where modified carbon paste electrode was employed as a detector. The factorial design showed the interaction between two principal factors, showing that the optimization by unidimensional studies would be impossible for this system. The electrode prepared with carbon paste modified with zeolite-containing porphyrin in its cavity give a high selectivity for the electrode in the hydrazine determination in flow system. Therefore, the optimized conditions showed high sensitivity and rapidity for the proposed method.

\section{References}

1. P. V. A. Pamidi and J. Wang, Electroanalysis, 8, 244 (1996).

2. W. Hou, H. Ji and E. Wang, Talanta, 39, 45 (1992).

3. G. Y. Vanag and M. A. Matskanova, J. Anal. Chem., 12, 149 (1957)

4. M. Issa and R. M. Issa, Anal. Chim. Acta, 14, 578 (1956).

5. J. Cihalik and K. Terebova, Chem. Listy, 50, 1768 (1956).

6. G. W. Watt and J. D. Chrisp, Anal. Chem., 24, 2006 (1952).

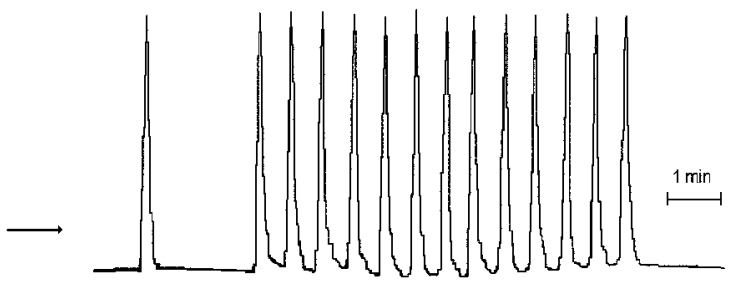

Fig. 5 Diagram obtained for the system after optimization using a hydrazine concentration of $25 \mu \mathrm{M}$, applied potential

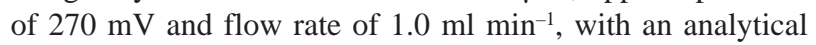
frequency of 70 injections per hour.

7. P. R. Wood, Anal. Chem., 25, 1879 (1953).

8. P. T. Kissinger and W. R. Heineman, J. Chem. Educ., 60, 702 (1983).

9. G. A. Mabbott, J. Chem. Educ., 60, 697 (1983).

10. T. J. Mafatle and T. Nyokong, J. Electroanal. Chem., 408 , 213 (1996).

11. J. Li and G. Calzaferri, J. Electroanal. Chem., 377, 163 (1994).

12. A. Walcarius, L. Lamberts and E. G. Derouane, Electroanalysis, 7, 120 (1995).

13. J. Wang and A. Walcarius, J. Electroanal. Chem., 407, 183 (1996).

14. C. Bing and L. Kryger, Talanta, 43, 153 (1996).

15. A. M. Tolbert and R. P. Baldwin, Anal. Lett., 22, 683 (1989).

16. K. N. Thomsen and R. P. Baldwin, Anal. Chem., 61, 2594 (1989).

17. J. Wang, T. Golden and R. Li, Anal. Chem., 60, 1642 (1988).

18. W. Hou and E. Wang, Anal. Chim. Acta, 257, 275 (1992).

19. S. V. Guerra, C. R. Xavier, L. T. Kubota and S. Nakagaki, Electroanalysis, 10, 111 (1998).

20. M. Valcarcel and M. D. Luque de Castro, "Anallisis por Inyeccion en Flujo", ed. Imprensa San Pablo, Cordoba, 1984.

21. B. Lu, M. R. Smyth, R. O'Kennedy, J. Moulds and T. Frame, Anal. Chim. Acta, 340, 175 (1998).

22. A. J. Downard, J. B. Hart, K. J. Powell and S. Xu, Anal. Chim. Acta, 269, 41 (1992).

23. J. Ruzicka and E. H. Hansen, "Flow Injection Analysis", Wiley, New York, 1981.

24. T. A. H. M. Janse, P. F. A. Van der Wiel and G. Kateman, Anal. Chim. Acta, 155, 89 (1983).

25. A. A. C. Matousek, J. L. Burguera, M. Burguera and C. Rivas, Talanta, 42, 701 (1995).

26. G. Henrion, R. Henrion, R. Heleisch and B. Boeden, Anal. Chim. Acta, 268, 115 (1992).

27. C. R. Xavier, S. Nakagaki, A. S. Mangrich and L. T. Kubota, Zeolite, in press.

28. B. G. Milagres, L. T. Kubota, G. de Oliveira Neto and E. L. Reis, J. Flow Injection Anal., 12, 223 (1996).

29. B. Barros Neto, I. S. Scarminio and R. E. Bruns "Planejamento e Otimizacao de Experimentos", Editora Unicamp, Campinas, 1995.

30. G. E. P. Box, W. G. Hunter and J. S. Hunter, "Statistics for Experimenters: An Introduction to Design, Data Analysis and Model Building", Wiley, New York, 1978.

(Received October 9, 1998) (Accepted August 9, 1999) 